Synthesis

\title{
A New Chemoselective Synthesis of Brombuterol
}

Marcelo S. Nery

Mariangela S. Azevedo

Jari N. Cardoso

Glaucia B. C. Slana

Rosangela S. C. Lopes*

Cláudio C. Lopes*

Synthesis 2007, 1471.

Detailed studies showed that the product formed is not brombuterol, but the isomer shown below. This isomer is presumably formed via an epoxide intermediate. We apologize for the misassignment.<smiles>CC(C)(C)NC(CO)c1cc(Br)c(N)c(Br)c1</smiles> 